\title{
Renal functions in patients with metabolic syndrome
}

\author{
Augusthy A. ${ }^{1}$, Sahu S. ${ }^{2}$, Ashok Kumar J. ${ }^{3}$, Jawalekar S. $^{4}$ \\ ${ }^{1}$ Dr. Asha Augusthy, Associate Professor, Department of Biochemistry, Sree Narayana Institute of Medical Sciences, \\ Ernakulam, Kerala, ${ }^{2}$ Dr. Suchanda Sahu, Associate Professor, Department of Biochemistry, All India Institute of Medical \\ Sciences, Sijua, Bhubaneshwar, Odisha, ${ }^{3}$ Dr. Ashok Kumar Jeppu, Associate Professor, Biochemistry unit, International \\ Medical School, Management and Science University, Shah Alam, Selangor, Malaysia, ${ }^{4}$ Dr. Seema Jawalekar, Professor, \\ Department of Biochemistry, GMC, Pali, Rajasthan, India.
}

Corresponding Author: Dr. Asha Augusthy, Associate Professor, Department of Biochemistry, Sree Narayana Institute of Medical Sciences, Ernakulam, Kerala. Email address:asha.augusty@gmail.com

\begin{abstract}
Introduction: Metabolic syndrome consists of a constellation of metabolic abnormalities that confer increased risk of diabetes mellitus. The aim of the present study was to study renal functions in patients with metabolic syndrome. Materials and methods: 50 controls and 50 individuals with metabolic syndrome were selected by purposive sampling technique. Waist circumference and blood pressure was measured and serum levels of fasting blood sugar, triglycerides and HDL were estimated and eGFR was calculated in controls and cases. Results: We found that serum urea andcreatininelevels were significantly increased andeGFR levels were significantly decreased in metabolic syndrome when compared to controls. Conclusion: Our study concluded that there is significant renal dysfunction in patients with metabolic syndrome.
\end{abstract}

Keywords: eGFR, Metabolic syndrome, Renal function

\section{Introduction}

Metabolic syndrome (MetS) consists of a constellation of metabolic abnormalities that confer increased risk of diabetes mellitus. The major features of the metabolic syndrome include central obesity, hypertriglyceridemia, low HDL cholesterol, hyperglycemia and hypertension [1].

Individuals with metabolic syndrome are at increased risk for developing chronic kidney disease (CKD) [2-5]. The mechanism behind this increased risk may be due to the aggregation of known risk factors for CKD in the metabolic syndrome diagnosis. On the other hand, the metabolic syndrome diagnosis may indicate the presence of insulin resistance, which may directly increase the risk for CKD [6].

Components and consequences of MetS, including diabetes mellitus and coronary heart disease, alter renal physiology and metabolism through a cascade of various reactions [7]. For example, obesity-related early renal changes increase the glomerular filtration rate

Manuscript received: $4^{\text {th }}$ November 2018

Reviewed: $14^{\text {th }}$ November 2018

Author Corrected: $18^{\text {th }}$ November 2018

Accepted for Publication: $21^{\text {st }}$ November 2018
(GFR) because of increased salt reabsorption by the proximal tubule. Consequent tubuloglomerular feedback mediated reduction in afferent arteriolar resistance results in increased glomerular capillary pressure [2]. The increased GFR is a compensatory response that restores salt balance despite continued increases in tubular reabsorption but contributes to renal injury, especially if it is combined with elevated blood pressure. In addition, obesity induced sleepapnea activates sympathetic nervous system increasing the tone of the glomerular efferent arterioles and the secretion of renin and angiotensin.

In patients with MetS, mildly elevated blood pressure or mild hyper-glycemiamay portend an increased risk of CKD. In addition, dyslipidemia may affect the prognosis of CKD as low HDL cholesterol was shown to be a predictor of faster CKD progression[8]. Recent evidence also indicated that presence of MetS is associated with an increased risk of developing CKD.

As a matter of fact, both MetS and CKD are major global health issues with regard to the increasing prevalence of obesity and aging society [9]. 


\section{Original Research Article}

The aim of this study is to find out the renal functions in metabolic syndrome.

\section{Materials and Methods}

Study design-The present study was conducted in the Department of Biochemistry, Father Muller's Medical College after obtaining clearance from institutional ethics committee.

The study group consisted of 100 individuals selected by purposive sampling technique who had come to hospital for health check-up during a time period of two years. Informed written consent was obtained from all individual participants included in the study. This was a case-control study with a sample size of 100 patients.

Selection of subjects- 50 individuals with metabolic syndrome (all patients who fulfil criteria for metabolic syndrome, according to National cholesterol education program (NCEP): ATP III 2001 for metabolic syndrome [10] and 50 controls were selected.

Exclusion criteria-Smokers, alcoholics, patients with history of liver and renal impairment were excluded from the study.

Sample and data collection- Forthe selected patients history was taken, physical examination was done. Waist circumference and blood pressure was measured.

Glomerular filtration rate (GFR) was estimated on the basis of serum creatinine level, with the most recent expression of the Modification of Diet in Renal Disease Study (MDRD) prediction equation for standardized serum creatinine [11]. eGFR was estimated using the recalibrated version of the four-variable MDRD study equation $\left\{\right.$ GFR $(\mathrm{ml} / \mathrm{min} / 1.73 \mathrm{~m} 2)=186 \times \mathrm{SCr}(\mathrm{mg} / \mathrm{dl})^{-}$ ${ }^{1.154} \mathrm{xage}^{-0.203} \times 0.742$ (if woman) $\}[12]$. In this study CKD was defined as eGFR $<60 \mathrm{ml} / \mathrm{min} / 1.73 \mathrm{~m} 2$.

The criteria was set according to the National Kidney Foundation-Kidney Disease Outcomes Quality Initiative (NKF-KDOQI).

The staging of CKD was categorized according to NKFKDOQI criteria based on different eGFR distribution: Stage 1>90ml/min, Stage 2:60-89ml/min, Stage 3:30$60 \mathrm{ml} / \mathrm{min}$, Stage $4: 15-29 \mathrm{ml} / \mathrm{min}$ and Stage $5: 15 \mathrm{ml} /$ $\min [13]$.

Plasma fasting blood sugar (FBS), serum HDL, serum triglyceride, serum ureaand serumcreatinine levels were estimated. Plasma FBS was estimated using glucose oxidase peroxidase method.

Triglycerides were estimated by enzymatic colour test glucose oxidase-peroxidase method.HDL was estimated by immune-inhibition enzymatic colour test.

All estimations were done on Olympus AU 400 autoanalyzer. Statistical analysis- The data was analysed by students paired t test and Pearson's correlation coefficient for relationship between variables.

Statistical analyses were performed with the help of SPSS software. For all statistical analyses the $p$ value was considered to be significant when $\mathrm{p}<0.05$.

\section{Results}

Table-1: Comparison of waist circumference, bloodpressure, FBS, HDL, triglycerides between the 2 groups

\begin{tabular}{|c|c|c|c|}
\hline & Control & Metabolic syndrome & p value \\
\hline Waist circumference(cm) & $91.56 \pm 4.82$ & $97.55 \pm 6.72$ & $<0.001$ \\
\hline $\begin{array}{c}\text { Systolic blood pressure } \\
(\mathrm{mm} \text { of Hg) }\end{array}$ & $0120.94 \pm 11.28$ & $131.84 \pm 14.55$ & 0.001 \\
\hline $\begin{array}{c}\text { Diastolic blood pressure } \\
(\mathrm{mm} \text { of Hg) }\end{array}$ & $77.58 \pm 7.05$ & $82.65 \pm 8.4$ & $<0.001$ \\
\hline FBS (mg/dl) & $99.27 \pm 9.15$ & $111.18 \pm 8.49$ & $<0.001$ \\
\hline HDL (mg/dl) & $45.12 \pm 7.84$ & $38.22 \pm 5.82$ & 0.002 \\
\hline
\end{tabular}

In our study we found that waist circumference, blood pressure, FBS, triglycerides were significantly increased in metabolic syndrome compared to controls. HDL cholesterol levels were significantly decreased in metabolic syndrome when compared to controls. 
Table-2: Comparison of urea,creatinine and eGFR between the 2 groups.

\begin{tabular}{|c|c|c|c|}
\hline & Control & Metabolic syndrome & p value \\
\hline Urea $(\mathrm{mg} / \mathrm{dl})$ & $22.36 \pm 5.18$ & $25.84 \pm 8.01$ & 0.012 \\
\hline Creatinine $(\mathrm{mg} / \mathrm{dl})$ & $0.88 \pm 0.14$ & $1.09 \pm 0.19$ & $<0.001$ \\
\hline $\mathrm{eGFR}(\mathrm{ml} / \mathrm{min})$ & $94.56 \pm 16.65$ & $75.28 \pm 15.13$ & $<0.001$ \\
\hline
\end{tabular}

We also found that serum urea and serumcreatinine were significantly increased in metabolic syndrome compared to controls. eGFR levels were significantly decreased in metabolic syndrome when compared to controls.

Table-3: Distribution of controls and metabolic syndrome with respect to GFR

\begin{tabular}{|c|c|c|}
\hline GFR(ml/min) & Controls & Metabolic syndrome \\
\hline $\begin{array}{c}\text { Stage 1 } \\
\text { Normal or High } \\
(>90)\end{array}$ & 32 & 9 \\
$(64 \%)$ & $(18 \%)$ \\
\hline $\begin{array}{c}\text { Stage 2 } \\
\text { Mildly decreased } \\
(60-89)\end{array}$ & $(36 \%)$ & 30 \\
\hline $\begin{array}{c}\text { Stage 3 } \\
\text { Moderately decreased } \\
(30-60)\end{array}$ & - & $11 \%)$ \\
\hline $\begin{array}{c}\text { Stage } 4 \\
\text { Severely decreased } \\
(15-29)\end{array}$ & - & - \\
\hline $\begin{array}{c}\text { Stage 5 } \\
\text { Kidney failure } \\
(<15)\end{array}$ & - & - \\
\hline Total & $\mathbf{5 0}$ & \\
\hline
\end{tabular}

In metabolic syndrome $18 \%$ of patients belonged to stage I, $60 \%$ belonged to stage 2 and $22 \%$ belonged to stage 3 whereas in controls $64 \%$ belonged to stage 1 and $36 \%$ belonged to stage 2 OF CKD.

\section{Discussion}

Metabolic syndrome is characterized as a cluster of metabolic disorders including central obesity, dyslipidemia, hypertension, and glucose intolerance [14]. There are some experimental and clinical evidence that implicated a causal link between increased BMI and increased risk of CKD $[15,16]$.

The possible mechanism for this link is through obesityrelated risk factors such as hypertension, dyslipidemia, and hyperglycemia, all components of metabolic syndrome [17].

In our study we found that waist circumference, blood pressure, FBS, triglycerides were significantly increased in metabolic syndrome compared to controls. HDL cholesterol levels were significantly decreased in metabolic syndrome when compared to controls. We found that serum urea and serum creatinine were significantly increased in metabolic syndrome compared to controls. eGFR levels were significantly decreased in metabolic syndrome when compared to controls. The renal dysfunction in metabolic syndrome may be due to individual components which are risk factors for the development of CKD. One of the risk factors for CKD is obesity and it is also correlated to insulin resistance [18].

The interaction between macrophages and adipocytes which are an important source of inflammatory and immunomodulatory factors leads to insulin resistance [19]. Studies which reported obesity as a significant risk factor for $e G F R<60 \quad \mathrm{ml} / \mathrm{min} / 1.73$ $\mathrm{m}^{2}$ used waist circumference rather than BMI [20-21].

In a study done by Lorraine S. Evangelista and coworkers found that general obesity and abdominal obesity were more prevalent in patients with CKD and abdominal obesity induces endocrine dysfunction or chronic inflammation thereby causing or worsening CKD [22]. Peter Stenvinkel and friends found that 


\section{Original Research Article}

excess fat mass promotes kidney disease directly as well as indirectly through hypertension, atherosclerosis, and type 2 diabetes [23]. Another risk factor for renal dysfunction is dyslipidemia. Studies done by Muntner P et al and to Ryu et al found that both high TG and low HDL cholesterol levels were associated with a significantly increased risk of CKD.

This is in accordance with our studies which showed high TG and low HDL. Dyslipidemia is closely related to glomerular capillary endothelial and mesangial cell as well as podocyte injury, which in turn leads to mesangial sclerosis. The glomerular mesangium due to accumulation of lipoproteins can stimulate matrix production and glomerulosclerosis [24].

Ivana Mikolasevic and friends concluded that dyslipidemia is seen in patients with CKD. They observed that patients with CKD suffer from hypertriglyceridemia due to the delayed catabolism and the increased hepatic production of triglyceride-rich lipoproteins.

They also noticed that there is decreased levels of HDL due to decreased levels of Apolipoprotein A I and A II, decreased activity of lecithin- cholesterol acyltransferase and increased activity of cholesterol ester transfer protein (CETP)[25].

Studies done by Daniel E Weiner et al [26] and Gearoid M. McMahon et al [27] also found that there is significant dyslipidemia in patients with CKD.

Type 2 diabetes mellitus and hypertension are significant and common risk factors for end stage renal disease .A study done by Banach $\mathrm{M}$ et al concluded that insulin resistance and central obesity have been considered the main factors involved in hypertension pathophysiology associated with MS [24].

Chen et al found that the risk of CKD was 2.6 times more in MetS. In obesity and MetS there is increased levels of C-reactive protein, tumor necrosis factor- $\alpha$, interleukin- 6 and oxidative stress in serum and adipose tissue due to chronic low grade inflammation .

This will end up in kidney damage due to progressive loss of nephrons and decline in GFR. Each component of MetS can potentially induce renal damage[28].

One main limitation of our study is that we have not analysed cystatin $\mathrm{C}$ and NGAL which are latest markers for renal dysfunction.

\section{Conclusion}

In the present study renal functions were assessed in terms of serum urea, creatinine and eGFR. It was found that serum urea, creatinine levels were significantly increased in patients with metabolic syndrome when compared with controls. eGFR levels were significantly decreased in metabolic syndrome when compared to controls. Our study concluded that there is significant renal dysfunction in patients with metabolic syndrome.

It is ideal to have periodic measurements of waist circumference, blood pressure and serum lipid profile and sugar levels to check the occurrence the metabolic syndrome which can lead to CKD.

Acknowledgment: We thank all the individuals forwillingly participating in this study. We thank Mrs. Harsha C.H, Asst. Professor in Biostatistics, Dept of Community Medicine, Sree Narayana Institute of Medical Sciences for helping us with the statistical analysis. We acknowledge the support of the management of Father Muller's Medical College and Laboratory staff.

\section{References}

1. Augusthy A, Sahu S, Ashok Kumar J, Jawalekar S, Marakala V, Thattil A. A comparison of BMI and Lipid Profile inpatients with metabolic syndrome and Type 2 Diabetes Mellitus. Int J Med Res Rev 2017;5(03):357362.doi:10.17511/ijmrr. 2017.i03.23.

2. Chen J, Muntner P, Hamm LL, et al. The metabolic syndrome and chronic kidney disease in U.S. adults. Ann Intern Med. 2004 Feb 3;140(3):167-74.

3. Kurella M, Lo JC, Chertow GM. Metabolic syndrome and the risk for chronic kidney disease among nondiabetic adults. J Am Soc Nephrol. 2005 Jul;16 (7): 2134-40. Epub 2005 May 18.DOI:10.1681/ASN. 2005010106

4. Chen J, Gu D, Chen CS, et al. Association between the metabolic syndrome and chronic kidney disease in Chinese adults. Nephrol Dial Transplant. 2007 Apr;22 (4):1100-6. Epub 2007 Feb 1.DOI:10.1093/ndt/gfl759

5. Luk AO, So WY, Ma RC, et al. Metabolic syndrome predicts new onset of chronic kidney disease in 5,829 patients with type 2 diabetes: a 5-year prospective analysis of the Hong Kong Diabetes Registry. Diabetes Care. 2008 Dec; 31(12): 2357-61. doi: 10.2337/dc080971. Epub 2008 Oct 3. 


\section{Original Research Article}

6. Johns BR,PaoAC,Kim SH.Metabolic syndrome, insulin resistance and kidney function in non-diabetic individuals.Nephrol Dial Transplant. 2012; 27(4): 1410 - 1415.doi: $10.1093 /$ ndt/gfr498.

7. Grundy SM. Metabolic syndrome scientific statement by the American Heart Association and the National Heart, Lung, and Blood Institute. Arterioscler Thromb Vasc Biol. 2005 Nov;25(11):2243-4. DOI:10.1161/01. ATV.0000189155.75833.c7

8. Maric C, Hall JE. Obesity, metabolic syndrome and diabetic nephropathy. Contrib Nephrol. 2011; 170: 28-35. doi: 10. 1159/ 000324941. Epub 2011 Jun 9.

9. Sheen YJ, Sheu WH. Metabolic syndrome and renal injury. Cardiol Res Pract. 2011 Mar 13;2011:567389. doi: $10.4061 / 2011 / 567389$.

10. Huang PL. A comprehensive definition for metabolic syndrome. Dis Model Mech. 2009 May-Jun;2 (5-6): 231-7. doi: 10.1242/dmm.001180.

11. Lin C, Li C, Liu Cet al. Risks of Decreased Renal Function and Increased Albuminuria for Glycemic Status and Metabolic Syndrome Components: Taichung Community Health Study. Bio Med Research International. 2014; Article ID 841497.https://doi. org/ 10. $1155 / 2014 / 841497$.

12. Delanaye P, Cohen EP. Formula-Based Estimates of the GFR: Equations Variable and UncertainNephron Clin Pract. 2008; 110:c48-c54.DOI: 10. 1159/000 151436 .

13. Zaman SB. Detection of Chronic Kidney Disease by Using Different Equations of Glomerular Filtration Rate in Patients with Type 2 Diabetes Mellitus: A CrossSectional Analysis.Cureus. 2017 Jun 14;9(6):e1352. doi: $10.7759 /$ cureus. 1352 .

14. Augusthy A, Jeppu AK, Sahu S, Jawalekar S, Marakala V, Iqbal S. A study of liver functions in metabolic syndrome and Type 2 diabetes mellitus. Int J Med Res Rev 2016;4(4):470-475. doi: 10.17511/ijmrr. 2016.i04.01.

15. Zoccali C, Mallamaci F. Adiponectin and leptin in chronic kidney disease: causal factors or mere risk markers? J Ren Nutr. 2011 Jan; 21(1):87-91. doi: 10. 1053/j. jrn.2010.10.014.
16. Gelber RP, Kurth T, Kausz AT, et al. Association between body mass index and CKD in apparently healthy men.Am J Kidney Dis. 2005 Nov; 46 (5): 871-80.

17. Thomas G, Sehgal AR, Kashyap SR, et al. Metabolic syndrome and kidney disease: a systematic review and meta-analysis. Clin J Am Soc Nephrol. 2011 Oct;6(10):2364-73. doi: 10.2215/CJN.02180311. Epub 2011 Aug 18.

18. Pinto-Sietsma SJ, Navis G, Janssen WM, et al. A central body fat distribution is related to renal function impairment, even in lean subjects. Am J Kidney Dis. 2003 Apr;41(4):733-41.

19. Bagby SP. Obesity-initiated metabolic syndrome and the kidney: a recipe for chronic kidney disease? J Am Soc Nephrol. 2004 Nov; 15 (11): 2775-91. DOI: 10. 1097 /01. ASN. 0000141965. 28037. EE.

20. Rashidi A, Ghanbarian A, Azizi F. Are patients who have metabolic syndrome without diabetes at risk for developing chronic kidney disease? Evidence based on data from a large cohort screening population. Clin J Am Soc Nephrol. 2007 Sep;2(5):976-83. Epub 2007 Aug 8.DOI:10.2215/CJN.01020207

21. Sun F, Tao Q, Zhan S. Metabolic syndrome and the development of chronic kidney disease among 118924 non-diabetic Taiwanese in a retrospective cohort. Nephrology (Carlton). 2010 Feb;15(1):84-92. doi: 10. 1111/j.1440-1797.2009.01150.x.

22. Evangelista LS, Cho WK, Kim Y. Obesity and chronic kidney disease: A population-based study among South Koreans. PLoS One. 2018 Feb 28;13 (2): e0193559. doi: 10.1371 /journal. pone. 0193559. e Collection 2018.

23. Stenvinkel P, Zoccali C, Ikizler TA. Obesity in CKD--what should nephrologists know? J Am Soc Nephrol. 2013 Nov;24(11):1727-36. doi: 10.1681/ASN. 2013040330. Epub 2013 Oct 10.

24. Kang YU, Kim HY, Choi JS, Kim CS, Bae EH, Ma SK, et al. Metabolic Syndrome and Chronic Kidney Disease in an Adult Korean Population: Results from the Korean National Health Screening. PLoS ONE. 2014; 9(5): e93795. https://doi.org/10. 1371/journal. pone. 0093795 . 


\section{Original Research Article}

25. Mikolasevic I, Žutelija M, Mavrinac V, et al. Dyslipidemia in patients with chronic kidney disease: etiology and management. Int $\mathbf{J}$ Nephrol Renovasc Dis. 2017 Feb 7;10:35-45. doi: 10.2147/IJNRD. S101 808. eCollection 2017.

26. Weiner DE, Sarnak MJ. Managing dyslipidemia in chronic kidney disease. J Gen Intern Med. 2004 Oct;19 (10) : 1045-52.
27. McMahon GM, Preis SR, Hwang SJ, et al. Midadulthood risk factor profiles for CKD. J Am Soc Nephrol. 2014 Nov; 25 (11): 2633-41. doi: 10.1681/ ASN. 2013070750. Epub 2014 Jun 26.

28. Kebapci N, Uslu S, Ozcelik E. Metabolic syndrome is a risk factor for the development of chronic renal disease. Ren Fail. 2013;35(4): 460-5. doi: 10.3109/ 0886022X. 2013.774680. Epub 2013 Mar 18.

\section{How to cite this article?}

Augusthy A, Sahu S, Ashok Kumar J, Jawalekar S. Renal functions in patients with metabolic syndrome. Int J Med Res Rev 2018; 6(08): 403-408. doi:10.17511/ijmrr.2018.i08.02. 